\title{
In vitro assessment of inter and intra batch variability of a breath-enhanced jet nebulizer
}

\author{
Mariam Rehman*, Antony Hurren, Adam Metcalf, Ross Hatley \\ From EAACI International Severe Asthma Forum (ISAF 2012) \\ Gothenburg, Sweden. 11-13 October 2012
}

\section{Background}

Guidelines recommend that patients presenting with acute severe asthma with life-threatening features receive the necessary high doses of $\beta 2$-agonists via the nebulized route.The SideStream Plus (SS+; Philips Respironics) is a breath-enhanced nebulizer designed to maximize respirable output, while minimizing treatment time [1]. Prior to the introduction of a new version of nebulizer, various in vitro assessments, including inter and intra batch variability, are performed using a limited number of devices. We present results of an analysis of inter and intra batch variability of SS+ nebulizers.

\section{Method}

SS + nebulizers ( 3 batches; $n=30$ per batch) were assessed in terms of 5 experimental parameters; nebulization time, residual volume, particle size distribution (mass median diameter (MMD), fine particle fraction (FPF)), and emitted dose. Each batch was provided with a driving flow from a different Porta-neb compressor (Philips Respironics). Measurement of particle size distribution was achieved using a laser diffractor (Malvern Spraytec) with an extraction flow of $15 \mathrm{l} / \mathrm{min}$. Each nebulizer was weighed and filled with $2.5 \mathrm{ml}$ salbutamol sulphate (albuterol sulfate) solution $(1 \mathrm{mg} / \mathrm{ml})$. To assess nebulization duration the nebulizers were run continuously until 'end of treatment', defined as when the obscuration level of the sample in the laser diffractor fell below $5 \%$ for $5 \mathrm{~s}$. At this point the SS+ were re-weighed to calculate residual volume. The dose delivered to a filter placed between the laser diffractor and extraction air flow was quantified using high performance liquid chromatography. The coefficient of variation $(\mathrm{CV})$ for each experimental parameter was calculated for each batch.

\section{Results}

Results are shown in Table1.

\section{Conclusion}

The intra batch coefficient of variation indicates that variability in each of the 5 experimental parameters did not differ substantially across the 3 batches tested. The close similarity between mean values for each of the experimental parameters indicates that inter batch variability was low. Taken together, these results suggest that different batches of SS + nebulizers should perform similarly in terms of nebulization time, particle size distribution, and emitted dose.

Table 1

\begin{tabular}{lllllll}
\hline & Batch A CV (\%) & Batch A mean & Batch B CV (\%) & Batch B mean & Batch C CV (\%) & Batch C mean \\
\hline Nebulization time (s) & 13.1 & 274 & 9.3 & 258 & 9.6 & 270 \\
Residual volume (mg solution) & 6.6 & 1035 & 8.1 & 1100 & 9.9 & 1086 \\
MMD $(\mu \mathrm{m})$ & 2.9 & 3.8 & 3.1 & 3.9 & 3.9 & 3.8 \\
FPF $(\%<5 \mu \mathrm{m})$ & 2.1 & 63.2 & 2.3 & 62.6 & 3.0 & 63.4 \\
Emitted dose $(\mu \mathrm{g}$ salbutamol) & 6.9 & 1127 & 9.2 & 1125 & 8.8 & 1101 \\
\hline
\end{tabular}


Published: 3 May 2013

\section{Reference}

1. British Guideline on the Management of Asthma: BTS/SIGN 2011 [http:// www.sign.ac.uk/guidelines/fulltext/101/index.html], (accessed 21 Aug 2012).

doi:10.1186/2045-7022-3-S1-P11

Cite this article as: Rehman et al: In vitro assessment of inter and intra batch variability of a breath-enhanced jet nebulizer. Clinical and

Translational Allergy 2013 3(Suppl 1):P11.

Submit your next manuscript to BioMed Central and take full advantage of:

- Convenient online submission

- Thorough peer review

- No space constraints or color figure charges

- Immediate publication on acceptance

- Inclusion in PubMed, CAS, Scopus and Google Scholar

- Research which is freely available for redistribution

Submit your manuscript at www.biomedcentral.com/submit
C Biomed Central 